\title{
Formação para a docência universitária: uma reflexão sobre o desafio de humanizar a cultura científica
}

\author{
Carlinda Leite \\ Universidade do Porto, Portugal \\ Kátia Ramos \\ Universidade Federal de Pernambuco, Brasil
}

\begin{abstract}
Resumo
Nos últimos anos a formação pedagógico-didáctica dos professores universitários tem vindo a constituir foco de atenção de várias instituições, situação que não era comum neste nível de ensino. A importância desta dimensão da docência esteve presente na Declaração Mundial sobre a Educação Superior (1998) e ganhou maior expressão com a Declaração de Bolonha (1999). É no reconhecimento de que a formação de professores do ensino superior tem de passar também pela componente pedagógicodidáctica que algumas instituições de ensino superior têm vindo a realizar acções de actualização que se constituem em espaços de reflexão sobre a docência. Sendo esta a problemática presente neste texto, nele caracterizamos desafios que se colocam à docência neste princípio do século XXI e analisamos uma experiência desenvolvida na Universidade do Porto, problematizando possibilidades destas acções se configurarem em espaços de diálogo entre a cultura humanística e a cultura científica e contribuírem para uma (re)contextualização de saberes e de fazeres.
\end{abstract}

Palavras-chave

Docência universitária; Formação docente universitária; Conhecimento pedagógico-didáctico

\section{Notas de introdução}

Quando se fala de professores dos ensinos básico e secundário é uma constante o reconhecimento de que o exercício da docência exige uma 
formação específica. No entanto, no caso do ensino superior esse reconhecimento nem sempre constitui uma referência, apesar de estar subjacente à Declaração Mundial sobre a Educação Superior no séc. XXI (UNESCO, 1998) e de se inferir a sua necessidade no cumprimento dos desígnios dos discursos do Processo de Bolonha iniciado com a Declaração de 1999. Na verdade, este Processo tem influenciado um discurso que vem convocando uma atenção especial à docência, apontando para a necessidade de romper com o paradigma focado no ensino para dar lugar ao que tem por meta a aprendizagem. Com tal propósito, em algumas instituições universitárias começaram a ser desencadeadas dinâmicas focadas em questões de ordem pedagógico-didáctica que reflectem a especificidade da docência neste nível de ensino e que, simultaneamente, têm viabilizado o reconhecimento da pertinência e da importância das humanidades para o desenvolvimento de uma reflexão desta ordem.

É no contexto desta situação que se situa o texto que aqui apresentamos e no qual, para tratarmos a questão da formação para e na docência universitária, seguimos uma estrutura focada em três pontos: o primeiro enuncia as novas exigências que se colocam à docência universitária; o segundo foca indícios do reconhecimento de um lugar para o conhecimento pedagógico-didáctico no ensino universitário; o terceiro, congregando dados de um movimento desencadeado na Universidade do Porto (U.Porto), dá a conhecer alternativas encontradas para possibilitar um diálogo entre a cultura humanística e a cultura científica, no contexto da docência universitária.

\section{Novos desafios para o Ensino Superior: exigências à docência universitária}

A transição na relação entre conhecimento, sociedade e universidade, situada no âmbito da crítica ao paradigma da racionalidade científica (Santos, 1996), tem colocado em xeque a condição da universidade como centro de produção e difusão do saber. De entre outros aspectos, a universidade é interpelada quanto à sua responsabilidade social diante de dicotomias que inviabilizam uma comunicação entre culturas e uma comunicação com o mundo do trabalho. No que respeita a esta dicotomia, e ao facto dela impossibilitar um modelo que tenha como base a assunção da 
responsabilidade social da Universidade, é reconhecida a necessidade de um ensino que contribua para superar a fragmentação de funções, ou seja, de um ensino profissional que, tendo um carácter propedêutico, se articule com a investigação e que esteja em sintonia com o contexto social.

Em Portugal, nestes últimos anos, assim como em muitos outros países europeus, o ensino superior tem-se confrontado com a adaptação ao chamado "Processo de Bolonha", isto é, com a incorporação nos currículos dos diversos cursos de princípios estabelecidos a nível europeu na Declaração de Bolonha (1999), nomeadamente os que decorrem do paradigma da formação. Uma análise dos discursos veiculados - e reafirmando o que em outro lugar sustentámos (Leite, 2006a, p. 290) permite concluir que eles têm apontado para uma formação que se estruture "na lógica da formação-acção, em vez da formação-transmissão e da mera obtenção de conhecimentos para aplicar na prática". E, nesta linha, apontam para uma metodologia possibilitadora de um ensino-aprendizagem cooperativo, para o desenvolvimento de competências interpessoais, para o recurso a processos de tutoria e de envolvimento efectivo dos actores educativos no processo de ensinar e de aprender.

Para estes mesmos princípios, e como também atrás afirmámos, tinha já apontado a Declaração Mundial sobre a Educação Superior no séc. XXI (UNESCO, 1998), nomeadamente quando questiona o conhecimento universitário de características disciplinares e quando aponta para a sua reconceptualização em termos de uma explícita responsabilidade docente no processo de aprendizagem dos estudantes. Ao mesmo tempo, o cumprimento das directrizes emanadas dos órgãos políticos para esta adequação ao Processo de Bolonha, para além de influenciar as concepções de ensinoaprendizagem a seguir no nível de ensino superior, tem condicionado a organização do tempo curricular dos cursos, agora estruturados no "sistema europeu de transferência de créditos" (ECTS), entendidos como "unidade de medida do trabalho do estudante e que, por isso, incluem as horas de contacto com os seus professores mas também as horas de estudo, de realização de trabalhos e de avaliação" (CRUP, 2003, p. 4). Como é evidente, esta organização curricular obriga a pensar, não apenas no tempo de ensino, mas também nas condições de aprendizagem, isto é, obriga a estruturar a formação em torno de uma forte relação do binómio ensino-aprendizagem. 
Ao mesmo tempo, para este mesmo sentido de formação aponta o facto de os cursos se terem de organizar em função, não apenas de conteúdos e de objectivos a atingir a curto prazo mas também de competências a desenvolver pelos estudantes, entendidas como algo que não é transmitido mas que é pessoalmente construído e desenvolvido (Leite, 2006a). Ou seja, e recorrendo a Jobert (2003), entendidas as competências como uma "inteligência prática", já que pressupõem a capacidade para desenvolver a inteligência no agir e em situações que jamais são iguais e estáveis. No quadro deste entendimento, podemos concluir que o conceito de formação que acompanha o chamado "discurso de Bolonha" não despreza os conhecimentos mas também não termina na sua aquisição, pois tem como mira desenvolver competências imprescindíveis à intervenção.

Sendo polimorfo o conceito de competência, vale a pena referir que não o associamos ao conceito de "desempenho", conceito esse que acompanhou as teorias curriculares e de educação dos paradigmas tecnicistas. Ou, dito de outro modo, não o limitamos ao conceito de "performance", criticado por Magalhães e Stoer (2002, p. 50) quando alertam para o "risco ao futuro e ao estilo da classe média" (idem, p. 48) quando a ênfase dos mandatos políticos e pedagógicos se desloca no sentido das "pedagogias visíveis", implicando "o abandono da pedagogia enquanto processo (com as suas características 'invisíveis')". Ao contrário, o conceito que nos enforma decorre de considerar que a organização do currículo e 0 processo do seu desenvolvimento em função de competências têm como intenção dar sentido social ao que se selecciona para ser ensinado e ao que se aprende e, por isso, estabelecer uma forte relação do saber escolar formal com as questões sociais.

Para a clarificação do conceito de competência, faz também sentido ter em conta as teorias de acção (Argyris, Putnam, \& Smith, 1985), nomeadamente quando lembram que o desenvolvimento das competências está relacionado com a representação que o/a autor/a faz e constrói de si, e não apenas dependente das características da situação. Em síntese, no conceito que nos orienta secundamos Lessard (2006, pp. 233-234), que afirma que "desenvolver competências não é tanto aprender comportamentos precisos e específicos - por assim dizer, extirpados tanto da experiência e da trajectória do sujeito como da situação, e assim objectivados e 
essencializados -, (...) mas antes mobilizar e combinar um conjunto de recursos cognitivos e não-cognitivos para levar em conta a complexidade da situação educativa e nela agir de modo finalizado, adaptado e eficaz". Neste sentido, a competência não é sinónimo de desempenho, perspectiva que corroboramos.

Constituindo um velho desafio fazer com que a formação mantenha maior relação com as situações que fazem parte da vida e das sociedades, em termos do discurso, o debate em torno dos compromissos de Bolonha tem gerado algum enfoque na necessidade de se repensar as competências desejadas no final dessa formação e de, em torno delas, delinear os planos curriculares e os programas das disciplinas que os promovam, entendendo-os no sentido que atrás conceptualizámos.

Como se depreende, esta nova orientação para a formação universitária implica novas formas de conceber o exercício docente. Se, até há uns anos atrás, às Universidades eram atribuídas apenas a missão de transmitir os conhecimentos que ao longo dos tempos vão sendo acumulados e de produzir novos conhecimentos através do envolvimento em investigação, agora, com esta concepção de formação, não pode ser descurada a criação de condições que assegurem a aprendizagem e a utilidade social dessa aprendizagem (Leite, 2006b). E, no quadro desta interpretação, o exercício da docência implica uma organização que prepare o sujeito para a aprendizagem autónoma, mas acompanhada, e onde exista um equilíbrio na relação exigências-apoio para essa aprendizagem. E é no quadro destes desafios que, no caso da Universidade do Porto, esta concepção justifica que um dos quatro objectivos estratégicos que orientam o projecto institucional seja atingir a excelência no ensino-aprendizagem.

O que estamos a afirmar não pressupõe, como é evidente, e como temos sustentado (Leite \& Ramos, 2007), que o exercício da investigação, na Universidade, não seja importante. Pressupõe, sim, a necessidade de, a par deste exercício, ser igualmente valorizado o ensino-aprendizagem. E, como aqui enunciamos, para realizar esta tarefa, os professores precisam de possuir conhecimentos pedagógico-didácticos que apoiem os estudantes na construção das suas aprendizagens.

Quando fazemos a apologia deste tipo de conhecimentos (pedagógico-didácticos) estamos a ter por referência um campo que diz 
respeito à compreensão das interacções humanas, no âmbito do carácter mediador do ensino e das suas relações, e que pretende viabilizar a identificação dos fundamentos da acção docente, tanto no que se refere à expressão de um ideário pedagógico, como à implicação desse trabalho no processo dos diálogos existentes e possíveis (Leite \& Ramos, 2009). Por isso, a justificação para a importância desta atenção a questões do domínio pedagógico-didáctico pode também ser encontrada se tivermos em conta o que em outro momento sustentámos: "as mudanças sociais que têm ocorrido na sociedade e os desafios para que se amplie o tempo de escolaridade têm tido como efeito a construção de uma escola de massas que se tem estendido ao ensino superior", que "os grupos hoje presentes no segmento universitário são cada vez mais diversos e distintos dos do passado", "têm motivações e expectativas variadas, experiências de vida múltiplas, idades diversificadas e níveis cognitivos distintos" (Leite, Lemos, \& Farinha, 2004, p. 3). Ou seja, tem de se reconhecer que os professores do ensino superior precisam de aprender a lidar com esta situação e de ensinar numa lógica distinta da homogeneidade.

Em síntese, consideramos importante a existência de formação para a docência pois reconhecemo-la como uma das condições para que os professores e a instituição cumpram esta sua função social. Neste sentido, reconhecemo-nos nas palavras de Zabalza (2004, p. 25) quando afirma que a Universidade, "de um lugar reservado a poucos privilegiados, tornou-se um lugar destinado ao maior número possível de cidadãos", acrescentando nós que a todos tem de criar condições de reconhecimento e de sucesso.

É também no quadro destas ideias que consideramos o princípio de indissociabilidade ensino-aprendizagem-investigação que permeia a dinâmica de construção, difusão e reconfiguração do conhecimento, superando a visão de que ensino e investigação são tarefas cumulativas, sendo compreendida como uma actividade integrada e efectivada através da relação pedagógica. Ou seja, o que estamos a afirmar é a necessidade de derrubar as barreiras da cultura científica, por Morin (2001, p. 17) caracterizada como aquela que "separa as áreas de conhecimento; acarreta admiráveis descobertas, teorias geniais, mas não uma reflexão sobre o destino humano e sobre o futuro da própria ciência". Neste sentido, apoiamos a existência de um diálogo com a cultura humanística que "alimenta a inteligência geral, enfrenta as grandes 
interrogações humanas, estimula a reflexão sobre o saber e favorece a integração pessoal dos conhecimentos" (ibidem).

Também a esse respeito, Zabalza (2004, p. 25) ressalta que "é necessário insistir exaustivamente que a formação deve servir para qualificar as pessoas, isto é, não é suficiente equipá-las com um perfil profissional padrão ou com uma determinada bagagem de conhecimento". E, nesta linha de pensamento, acrescenta aspectos sobre o sentido de uma formação universitária, ressaltando que ela exige contemplar o desenvolvimento pessoal, articulado ao desenvolvimento de conhecimentos e de competências específicas, e possibilitar uma visão mais ampla do mercado de trabalho a fim de criar condições para nele agir com maior autonomia (idem, p. 45). Ou seja, estes desafios requerem o que Barnett (2002) indica como condições para o transitar numa era de supercomplexidade, a saber: a interdisciplinaridade crítica; a reflexão colectiva; a renovação premeditada; a capacidade para mover as fronteiras; o compromisso participativo; e a tolerância comunicativa.

Pelo que temos vindo a enunciar, podemos aceitar a tese defendida por Zabalza (2004, p. 102) quando afirma que a docência universitária exige "desaprender, eliminar resquícios, desconstruir práticas, significados e prioridades que fazem parte da tradição institucional", pois para aprender a pensar e agir em outra lógica é preciso desconstruir a lógica vigente. E recorrendo ainda a este autor, "desaprender traduz-se na capacidade de 'desconstruir' a situação vigente do sistema, de seus significados e de suas práticas e de 'reconstruí-la' com um novo significado ou com um novo tipo de intervenções, o qual será o conteúdo da aprendizagem" (idem, p. 104).

Diante destas observações, parece-nos fazer sentido que a UNESCO (1998), ao reconhecer a necessidade de focar o processo de ensinoaprendizagem no estudante, apele para uma necessária atenção às questões pedagógico-didácticas na universidade e para que os docentes se apropriem de um conhecimento que possibilite dar conta do seu exercício profissional, no sentido de que é tempo de desaprender para poder reconstruir, aspectos que, de certo modo, atravessam também os discursos que acompanham o processo de Bolonha. 


\section{Reconhecendo a especificidade da docência e de um lugar para o conhecimento pedagógico-didáctico no ensino universitário}

$\mathrm{Na}$ continuidade das ideias que temos aqui vindo a desenvolver, é inevitável afirmar-se que o ensino só se justifica se gerar aprendizagem e permitir a obtenção de pré-requisitos que sejam mobilizados na construção de novas aprendizagens. Ao mesmo tempo, começa também a ser reconhecida e recorrentemente afirmada a necessidade (ou pelo menos a importância) de que a obtenção desses conhecimentos seja acompanhada de situações que dêem relevo à sua utilidade social.

Nesta perspectiva, e no que à universidade diz respeito, esta necessidade (ou esta importância) é acrescida pela responsabilidade que advém do perfil de formação que se deseja que nela ocorra e que exige competência para contextualizar e fundamentar saberes e fazeres. Ou seja, e corroborando Bourdoncle e Lessard (2002, p. 16), a universidade "já não pode limitar-se a dar uma formação geral e liberal, nem uma formação científica, ignorando a maneira como os estudantes poderão depois ganhar a sua vida". Conforme ainda esses autores, é necessário que haja "um novo equilíbrio que tenha em conta as especificidades das formações profissionais que a sociedade espera hoje da universidade, sem que ela abandone por isso a sua função crítica" (idem, p. 152)

Em síntese, podemos inferir que esta concepção aponta para uma formação orientada para o desenvolvimento de competências que se expressam no agir (no sentido que atrás lhe apontámos) e que, por isso, configura uma marca na estrutura dos planos curriculares e um entendimento da docência distinto do que a restringe aos modos de trabalho pedagógico do tipo transmissivo (Lesne, 1984). E, uma vez mais reforçamos, este entendimento da docência exige um conhecimento pedagógico-didáctico que leve, quem ensina, a potenciar, em quem tem a tarefa de aprender, a mobilização de processos de um forte envolvimento na construção e na regulação da aprendizagem, ou seja, exige reconhecer que a acção docente é "saber fazer aprender alguma coisa a alguém", como afirma Roldão (2000, p. 17).

Ora, é este reconhecimento de um saber-fazer que confere especificidade à acção docente e é ele que justifica um lugar para o 
conhecimento pedagógico-didáctico que supere a visão reducionista de que basta, para se ser professor, o conhecimento da área específica a que cada docente se encontra vinculado. Isto é, é este reconhecimento de que existe um saber específico para o exercício da docência que contraria a visão de que quem sabe, automaticamente sabe ensinar e também a de que só quem sabe investigar, pode realmente ensinar (Bourdoncle \& Lessard, 2002).

Como no início deste texto afirmámos, contrariamente ao que acontece para a docência nos ensinos básico e secundário - onde é exigida uma formação específica para o exercício da docência -, no ensino universitário a maior parte dos professores tornou-se professor sem qualquer formação específica para ser docente, apoiando-se, para este fazer, apenas na sua experiência de aluno e na experiência que a prática lhe vai fornecendo, situação que é evidenciada em vários estudos (Cunha, 2007; Esteves, 2005; Zabalza, 2004).

A agravar esta situação, realce-se que, em Portugal, a entrada e, de um modo geral, a progressão na carreira universitária tem sido marcada pelo envolvimento na investigação, sendo ignorada, ou pelo menos descurada, a componente pedagógica, contrariamente ao que se passa em outros níveis de ensino. Este facto, mesmo que não compreensível quando se esperava do trabalho docente uma orientação normalizadora, é perfeitamente desajustado quando o ensino superior se confronta com situações de uma grande diversidade de públicos e de situações e quando dele se espera uma formação para lidar com a multidimensionalidade e para conviver com a imprevisibilidade e a provisoriedade. Ou, como referem Inayatullah e Gidley (2003, p. 37), quando se espera dos professores competência para apoiarem os estudantes no desenvolvimento intelectual, emocional e espiritual, e quando deles se espera que compreendam as condicionantes em diálogo das aspirações sociais com as colectivas, situando no tempo e no espaço o conhecimento adquirido.

Dispensando o devido cuidado de não atribuir à formação pedagógicodidáctica um poder redentor mas, sim, o de ressaltar o seu carácter mediador, encaramo-la como a possibilidade de delinear a necessária reflexão sobre a especificidade docente universitária - no contexto do desafio de superar o "divórcio" entre a cultura humanística e a cultura científica (Morin, 2001). E fazemos esta inferência nomeadamente por reconhecermos que tal 
separação, além de polarizar análises, constitui um obstáculo à compreensão do fenómeno educativo na sua complexidade.

Em função disso, consideramos que a docência, para ultrapassar a barreira disciplinar, antes de tudo, necessita de se situar como uma profissão de interacções humanas, nomeadamente no contexto da compreensão da docência como "um trabalho cujo objecto não é constituído de matéria inerte ou de símbolos, mas de relações humanas com pessoas capazes de iniciativa e dotadas de uma certa capacidade de resistir ou de participar da acção dos professores" (Tardif \& Lessard, 2005, p. 35). Tal concepção situa a responsabilidade docente para com o outro, bem como indicia o reconhecimento de um corpo de conhecimentos que possibilitem organizar o trabalho de docência para dar suporte a esta interacção - não como prescrição, mas como fundamentos estruturantes que permitam uma compreensão deste trabalho.

Articulando o que estamos a afirmar com ideias que matriciam o Processo de Bolonha, nomeadamente as que são expressas no documento sobre o papel das universidades (Comissão das Comunidades Europeias, 2003), realçamos o facto de nele ser apontado que "o mundo académico necessita urgentemente de se adaptar ao carácter interdisciplinar dos campos abertos pelos grandes problemas de sociedade, como o desenvolvimento sustentável" (idem, p. 9). Esta observação é feita em função da constatação de que as actividades de ensino, nas universidades, "tendem a permanecer organizadas, e ainda muitas vezes compartimentadas, em função do quadro disciplinar tradicional" (ibidem). Ao mesmo tempo, esta compreensão deixa claro que é preciso muito mais do que o domínio de uma área disciplinar, bem como o reconhecimento da especificidade da função docente. Ou seja, e como afirma Zabalza (2004, p. 108), "como em qualquer outro tipo de actividade profissional, os professores devem ter os conhecimentos e as habilidades exigidos a fim de poder desempenhar adequadamente as suas funções". Com isto, Zabalza opõe-se à ideia de que ensinar se aprende na prática, pois entende que por a docência implicar desafios e exigências, são necessários conhecimentos específicos para exercê-la, isto é, "conhecimentos e competências próprios, preparação específica, requisitos de ingresso, plano de carreira profissional" (idem, p. 109). 
É também no quadro destas ideias que reconhecemos indícios da necessidade de um conhecimento pedagógico-didáctico que dê suporte a este exercício, justificando tal facto na explicitação da responsabilidade intrínseca à docência e na necessidade de se ter competências académicas e profissionais para tal.

Secundando Esteves (2005, p. 1), quando afirma que é recente "a manifestação de interesse científico, profissional e político pela qualidade pedagógica de que se reveste o trabalho docente no ensino superior", compreendemos o debate acerca do lugar do conhecimento pedagógicodidáctico na docência universitária. $E$ é por termos essa compreensão que temos vindo a sustentar a necessidade de saberes teóricos que apoiem a reflexão sobre a prática e a acção docente e que, para a demonstrar, recorremos a um movimento em que estamos envolvidas na Universidade do Porto, no contexto do Grupo de Investigação e Intervenção Pedagógicas da Universidade do Porto (GIIPUP), que se tem constituído como um desafio para a institucionalização de formação pedagógico-didáctica de docentes desta universidade, através do diálogo entre a cultura científica e a cultura humanística.

\section{Em busca de humanizar a cultura científica: caminhos delineados na Universidade do Porto}

Embora seja um lugar-comum designar a universidade como a instituição onde tem lugar a dimensão analítico-crítica, criativa e reflexiva da produção de conhecimento e da sua difusão, as reservas que evidenciam a tendência para a cristalização, para o fechamento na cultura científica e para uma prática de ensino centrada no conteúdo indicam a existência de uma distância entre os princípios discursivos e o efectivo funcionamento das instituições universitárias (Morin, 2001).

A tradição de centro de produção e difusão do conhecimento contribuiu para uma auto-suficiência da universidade que esteve muitas vezes na base de uma isenção de reflexão sobre esse processo de produção e difusão principalmente no que respeita ao ensino e à aprendizagem nela desenvolvidos. Ou seja, apesar de esta instituição ser idealizada como crítica e criativa, o corporativismo - decorrente muitas vezes da forma de 
recrutamento de pessoal (Zabalza, 2004) - favoreceu uma tendência para a cristalização e para a desestimulação de questionamentos sobre as bases do processo de fazer aprender.

No contexto das alterações ocorridas na relação sociedade, conhecimento e universidade, a instituição universitária começa também a ser requisitada para assumir uma responsabilidade social, no que se refere a acompanhar o ritmo acelerado do desenvolvimento tecnológico, sem perder de vista a criticidade e a criatividade para uma efectiva intervenção humana. Fazendo uma interpretação dessa ordem de acontecimentos, Rodrigues (2005, p. 2) aponta que "a sociedade do conhecimento substitui progressivamente a sociedade industrial e gera novas demandas ao ensino superior, quer enquanto sustentáculo da inovação científica e tecnológica quer enquanto instância de formação por excelência".

$\mathrm{Na}$ Universidade do Porto, depois de já terem existido algumas tentativas institucionais para organizar formação dos seus docentes, sem, no entanto, terem gerado continuação, teve lugar, em 2005, uma Acção Piloto de Actualização Pedagógico-Didáctica de Docentes da Universidade do Porto que teve como objectivo incentivar reflexões sobre desafios que se colocam à docência universitária, através de troca de experiências entre docentes sobre o exercício profissional docente (IRICUP/FPCEUP, 2005). Esta Acção Piloto, apoiada na concepção de que o trabalho docente é uma acção que, de acordo com Therrien (2002, p. 106), "se desenrola em um processo desenvolvido por meio de constantes tomadas de decisão de um sujeito mediador e articulador de múltiplos elementos que condicionam o seu desempenho e os resultados pretendidos", organizou-se de modo a criar as bases para um processo de reflexão pessoal e institucional acerca da docência universitária.

A opção seguida nesta formação, e como já atrás indiciámos, teve por base a ideia, nas palavras de Tardif (2002, p. 11), de que o docente, "ao escolher ou privilegiar determinados procedimentos para atingir seus objectivos em relação aos alunos, (...) assume uma pedagogia (...) embora se manifeste com frequência uma pedagogia sem reflexão pedagógica". $\mathrm{Na}$ selecção das temáticas considerou-se também importante que os professores conheçam o sistema em que estão inseridos, as finalidades que o orientam, os princípios gerais de organização e desenvolvimento do currículo (Leite, 2007), não se ignorando estas dimensões. Nesta posição corroborou-se 
Therrien (2002) quando aponta para as acções, para além de situarem o docente na categoria de sujeito epistémico, necessitam de incorporar questões do contexto de decisões político-ideológicas, que não se restringem a posturas pessoais, mas que se ampliam ao âmbito institucional.

Igualmente nesta posição apoiou-se Gimeno Sacristán (1995, p. 76) quando afirma que a "formação contínua de professores deve pôr em causa as bases da profissionalidade docente, não se limitando a uma reciclagem ao nível dos conteúdos ou das destrezas". Por isso, no caso a que nos estamos a reportar da U.Porto, a condução dos trabalhos caracteriza-se por uma orientação em que o foco da atenção nas acções é a profissionalidade docente, principalmente no que respeita à compreensão do contexto que a configura e a institui.

Talvez por ter por suporte estas ideias, no final da Acção Piloto a que atrás nos referimos, os elementos nela envolvidos manifestaram o desejo de dar continuidade ao movimento de reflexão iniciado, reivindicando a sua institucionalização como grupo de investigação e intervenção na U.Porto, o que levou à constituição do Grupo de Investigação e Intervenção Pedagógicas da Universidade do Porto (GIIPUP).

Do conjunto das actividades realizadas pelo GIIPUP, realçamos aqui as sessões de Saberes Partilhados por considerarmos que estão a permitir gerar uma reflexão da prática docente, centrada em processos de ensinoaprendizagem, a partir do que vem sendo desenvolvido no exercício da docência, reflexão essa que tem possibilitado evidenciar uma forte relação integradora entre ensino e investigação. As sessões realizadas desenrolaramse a partir da apresentação de experiências de fazeres docentes que permitiram tornar evidente a importância de investigar processos de ensinoaprendizagem, bem como partilhar colectivamente pontos de vista enquadrados em referenciais teóricos das Ciências da Educação, referenciais esses que fornecem uma compreensão mais profunda do fazer-docente.

Como esquema organizativo destas sessões, cada docente convidado a partilhar a sua experiência, na sua apresentação, tem situado os motivos que justificam optar pelos processos de ensino-aprendizagem encontrados, o modo como tem organizado e desenvolvido esse ensino e como tem perspectivado a aprendizagem. Ao mesmo tempo, tem havido lugar também para a avaliação da consecução dos processos pedagógico-didácticos 
seguidos pelos diversos elementos, bem como dos efeitos por eles gerados e do balanço que é feito pelos estudantes. O debate que se tem seguido a essas apresentações também tem permitido reflectir sobre as possibilidades e os limites dessas várias opções pedagógico-didácticas e sobre os vários modos de trabalho pedagógico.

Como ponto comum, nestas sessões tem sido identificado que a opção pelo redimensionamento do fazer-docente decorre da investigação sobre esse mesmo fazer - entendido como busca de uma solução para resolver problemas que esse fazer-docente suscita. Concretizando, nos casos até agora apresentados, a identificação de problemas que vão surgindo no fazerdocente - e que se prendem muitas vezes com razões da dificuldade de estudantes acompanharem o processo de ensino e identificarem alternativas que possibilitem a aprendizagem - esteve na origem destes professores procurarem outras alternativas e outros procedimentos didácticos.

Apesar deste olhar positivo que construímos e veiculamos sobre o que está a acontecer na U.Porto, temos de reconhecer, e como já em outro lugar foi sustentado (Leite, 2007, p. 7), que, em muitos casos, a procura de formação por docentes desta Universidade tem ocorrido mais em função de esperarem das Ciências da Educação "técnicas e instrumentos que mecanicamente possam aplicar na prática docente, e não dispositivos que, permitindo globalmente enquadrar a educação e a actual missão da Universidade, conduza a um processo de construção pessoal capaz de proporcionar reequacionamentos do exercício profissional". No entanto, e como nesse mesmo lugar foi afirmado, reconhecendo "a aula como espaço nuclear da formação, pois nela convergem os saberes e os investimentos científicos, pedagógicos e culturais" (idem, p. 12), cremos que esta focagem poderá "abrir portas para saberes de outras áreas disciplinares" (ibidem) das Ciências da Educação.

Em síntese, podemos afirmar que estas sessões têm vindo a possibilitar caminhos de reconhecimento da investigação como uma actividade quotidiana, no sentido em que têm focado aspectos de acompanhamento dos processos de ensino e de aprendizagem, isto é, têm apontado para possibilidades de relacionar ensino e investigação de forma integrada. Acreditamos, também, que os docentes que até agora, nestas sessões, têm apresentado os seus trabalhos e os que nelas têm participado 
têm ampliado os horizontes do campo científico de origem e reconhecido a necessidade de olhar o ensino de uma forma interdisciplinar, onde questões de relação, de interacção e de intervenção não podem ser descuradas.

Como se depreende, no exemplo desta acção do GIIPUP a que aqui nos estamos a reportar - Saberes Partilhados - estamos a considerar que a investigação constitui uma oportunidade de recolher informações que apoiem a reflexão sobre percursos de mediação didáctica, e que, por isso, forneçam elementos que permitam continuar ou redefinir caminhos de acção. E estamos a considerar que, para tal, é importante o recurso a um conhecimento balizador oriundo das Ciências da Educação que apoie a identificação do carácter relacional na acção pedagógica, a partir de uma contextualização do conhecimento científico em seu carácter social, interdisciplinar, político e cultural. Ou seja, estamos a convocar uma leitura científica das situações, assumindo que a sua objectividade resulta de subjectividades.

\section{Considerações finais}

Sendo a intenção deste texto, e como o próprio título indicia, afirmar a necessidade e a importância da formação para o exercício da docência no ensino universitário, nele demos atenção especial aos desafios sociais e educacionais que têm vindo a ser colocados a este nível de ensino e ao movimento do grupo GIIPUP da Universidade do Porto, que tem centrado a sua atenção em questões de ordem pedagógico-didáctica.

A acção deste grupo (GIIPUP) parte da crença de que o exercício da docência exige um conhecimento específico - que aqui designámos por conhecimento pedagógico-didáctico - e que esse conhecimento é importante para assegurar a integração da tríade ensino-aprendizagem-investigação e para humanizar a cultura científica. Se, no princípio dos anos 70, em Portugal, era considerado um bom professor, ou uma boa professora, aquele/a que conseguia despertar a atenção dos alunos para os conteúdos do programa, que expunha e explicava os assuntos num discurso e numa lógica passíveis de serem compreendidos pelos alunos e que os estimulava ao cumprimento de um certo número de tarefas que ajudassem à aquisição e compreensão desses conteúdos, hoje, esta pergunta feita a estudantes ou a professores gera respostas que vão muito para além do ensino e da transmissão de 
conhecimentos. É disso exemplo o conjunto de definições enunciadas por professores da Universidade do Porto envolvidos em algumas das acções de formação pedagógico-didáctica promovidas pelo GIIPUP quando afirmam:

"é aquele que consegue que os alunos atinjam desenvolvimento das capacidades o mais elevado possível, no contexto em que ensina";

"o que é capaz de mobilizar para aprender, despertar interesse";

"é aquele que apoia o desenvolvimento de competências pessoais e profissionais";

"é aquele que cria autonomia, independência, o que interage";

"é aquele que tem capacidade de comunicar estabelecendo uma relação empática e conseguindo chegar às dificuldades do aluno";

"é aquele que tem clareza, que é um modelo para o aluno, que contribui para o desenvolvimento da autonomia nos alunos";

"uma pessoa cuja trajectória pessoal, a constante actualização, a gestão do tempo de aprendizagem e a necessidade de incentivar a auto-aprendizagem e o espírito crítico sejam referenciais que possibilitem compreender o seu trabalho no contexto da verticalidade e horizontalidade da formação no curso".

Como se depreende, estes conceitos de 'bom professor' não se esgotam no saber científico nem numa orientação enfeudada em teorias do racionalismo académico que fazem do saber centrado nas disciplinas clássicas o foco principal do ensino e do acto de transmissão de conhecimentos e da organização estrutural dessa transmissão a actividade exclusiva dos professores (Leite, 2002). Ou seja, estas concepções de 'bom professor' rompem com as perspectivas que enfatizam o ensino, e não a aprendizagem, e que concebem o currículo como um plano de instrução e a actividade docente como o meio de socializar as novas gerações no desenvolvimento de uma racionalidade que cultiva a dimensão cognitiva e a herança cultural (Leite, 2003).

Como é evidente, estas perspectivas de 'bom professor' articulam-se com concepções de formação características de um tempo e de uma orientação teórico-prática que desejamos ser considerada do passado, pois concordamos com Lopes (2001, p. 343) quando afirma que "se algo se destaca da história longínqua e recente dos professores é a sua incessante dependência, exercida pelo poder político sim, mas sobretudo conseguida 
pela racionalidade dominante que Ihes retirou sistematicamente o seu principal material de trabalho: o saber emancipatório". E apoiamo-la também quando aponta a necessidade de alternativas que permitam "re-significar esse projecto emancipatório para uma tomada do sentido da profissão no novo contexto social" (ibidem).

É neste sentido que encaramos a formação pedagógico-didáctica como um meio de propiciar condições a um exercício da docência resignificado e que sustente práticas de uma aprendizagem emancipatória. Apoiamos Miguel Zabalza quando, a propósito dos modos de docência, fala da existência de "coreografias pobres" e de "coreografias ricas" - quanto à capacidade que têm de gerar aprendizagens nos estudantes - e quando insiste na "necessidade de considerar os contextos e as condições em que se produzem os processos de aprendizagem" (Zabalza, 2006, p. 11), já que, como diz, estes elementos "predeterminam o processo em si e, logicamente, os seus resultados" (ibidem). E é na base desta ideia que temos vindo a apontar a importância de um conhecimento pedagógico-didáctico que apoie a configuração de uma aprendizagem efectiva dos estudantes, no contexto de uma autonomia que, progressivamente, precisa de ser menos apoiada. E é também por isso que sustentamos a importância de uma formação de docentes do ensino superior orientada por princípios de um forte comprometimento colectivo em processos de reflexão sobre o que se passa na aula, mas também sobre o que se passa fora dela e fora da instituição universitária, lugar esse que humaniza e socializa a cultura científica.

\section{Referências}

Argyris, C., Putnam, R., \& Smith, D. M. (1985). Action science. San Francisco/London: Jossey-Bass Publishers.

Barnett, R. (2002). Claves para entender la universidad - En una era de supercomplejidad. Barcelona: Ediciones Pomares.

Bourdoncle, R., \& Lessard, C. (2002). Qu'est-ce qu'une formation professionnelle universitaire? Conceptions de l'université et formation professionnelle. Revue Française de Pédagogie, 139, 131-154.

Comissão das Comunidades Europeias (2003). O papel das universidades na Europa do conhecimento. Disponível em http://www.mctes.pt/docs/ficheiros/ PapelUniversidades.pdf (acesso em 16 de Fevereiro de 2008). 
CRUP - Conselho de Reitores das Universidades Portuguesas (2003) [doc. policopiado].

Cunha, M. I. (2007). O lugar da formação do professor universitário: A condição profissional em questão. In M. I. Cunha (Org.). Reflexões e práticas em pedagogia universitária (pp. 11-26). Campinas: SP: Papirus.

Esteves, M. (2005). Melhorar a pedagogia do ensino superior. In Actas VIII Congresso SPCE - Cenários da educação/formação: Novos espaços, culturas e saberes. Castelo Branco, Portugal.

Gimeno Sacristán, J. (1995). Consciência e acção sobre a prática como libertação profissional dos professores. In A. Nóvoa (Org.), Profissão professor (pp. 6169). Porto: Porto Editora.

Inayatullah, S., \& Gidley, J. (2003). Introdución: Las fuerzas que configuran los futuros de la universidad. In S. Inayatullah \& J. Gidley (Orgs.), La universidade en transformación: Perspectivas globales sobre los futuros de la universidad (pp. 7-24). Barcelona: Ediciones Pomares.

IRICUP/FPCEUP (2005). Acção de actualização pedagógico-didáctica de docentes da UP - Acção Piloto - (Abril-Junho) - Documento de apresentação. Porto: Universidade do Porto.

Jobert, G. (2003). De la qualification à la compétence. Entretien avec Guy Jobert. Sciences Humaines, 40, 36.

Leite, C. (2002). O currículo e o multiculturalismo no sistema educativo português. Lisboa: Fundação Calouste Gulbenkian/FCT.

Leite, C. (2003). Para uma escola curricularmente inteligente. Porto: Edições ASA.

Leite, C. (2006a). Entre velhos desafios e novos compromissos, que currículo para a formação de professores? In A. Silva et al. (Orgs.), Novas subjetividades, currículo, docência e questões pedagógicas na perspectiva da inclusão social (pp. 277-298). Recife: Edições Bagaço.

Leite, C. (2006b). Percursos e tendências recentes da formação de professores em Portugal. Revista Educação, 3(57), 371-389.

Leite, C. (2007). Que lugar para as Ciências da Educação na formação para o exercício da docência no Ensino Superior? In IX Congresso SPCE - Educação para o sucesso: Políticas e actores. Funchal: UMa.

Leite, C., Lemos, M., \& Farinha, J. (2004). Preparação e avaliação pedagógica dos docentes [doc. policopiado].

Leite, C., \& Ramos, K. (2007). Docência universitária: Análise de uma experiência de formação na Universidade do Porto. In M. I. Cunha (Org.), Reflexões e práticas em pedagogia universitária (pp. 27-42). Campinas, SP: Papirus.

Leite, C., \& Ramos, K. (2009). Pedagogía universitaria: Una contribución para la visibilidad de la dimensión pedagógico-didáctica de la docencia. In B. Arciga Zavala (Ed.), Contextos, identidades y academia en la Educación Superior (pp. 89-114). México: Plaza y Valdés Editores.

Lesne, M. (1984). Trabalho pedagógico e formação de adultos. Lisboa: FCG. 
Lessard, C. (2006). A universidade e a formação profissional dos docentes: Novos questionamentos. Educação \& Sociedade, 27(94), 223-249.

Lopes, A. (2001). Libertar o desejo, resgatar a inovação. A construção de identidades profissionais docentes. Lisboa: ME/IIE.

Magalhães, A., \& Stoer, S. (2002). A escola para todos e a excelência académica. Porto: Profedições.

Morin, E. (2001). A cabeça bem-feita: Repensar a reforma, reformar o pensamento (4 ed.). Rio de Janeiro: Bertrand Brasil.

Rodrigues, A. (2005). Formação pedagógica dos docentes do Ensino Superior: Desafio de Bolonha? In Actas VIII Congresso SPCE - Cenários da educação/formação: Novos espaços, culturas e saberes. Castelo Branco, Portugal.

Roldão, M. C. (2000). Os desafios da profissionalidade e o currículo. Aveiro: CIFOP.

Santos, B. (1996). Um discurso sobre as ciências (8 ${ }^{\mathrm{a}}$ ed.). Porto: Edições Afrontamento.

Tardif, M. (2002). Saberes docentes e formação profissional ( $2^{\mathrm{a}}$ ed.). Petrópolis, RJ: Vozes.

Tardif, M., \& Lessard, C. (2005). O trabalho docente: Elementos para uma teoria da docência como profissão de interações humanas. Petrópolis, RJ: Vozes.

Therrien, J. (2002). O saber do trabalho docente e a formação do professor. In A. Shigunov Neto \& L. Maciel (Orgs.), Reflexões sobre a formação de professores (pp. 103-114). Campinas, São Paulo: Papirus.

UNESCO (1998). Declaración mundial sobre la Educación Superior en siglo XXI: Visión y acción. Disponível em http://www.unesco.org/education/educprog/wche/ declaration_spa.htm (acesso em 6 de Agosto de 2006).

Zabalza, M. (2004). O ensino universitário: Seu cenário e seus protagonistas. Porto Alegre: Artmed.

Zabalza, M. (2006). Uma nova didáctica para o ensino universitário: Respondendo ao desafio do Espaço Europeu de Educação Superior. Porto: Universidade do Porto. 
TRAINING FOR UNIVERSITY TEACHING: A REFLECTION ON THE CHALLENGE OF HUMANIZING THE SCIENTIFIC CULTURE

\section{Abstract}

During the last years the pedagogical and didactical training of university teachers has become the focus of several institutions, a situation that was not common at this level of education. The importance of this aspect of teaching was present in the World Declaration on Higher Education (1998) and won more expression with the Bologna Declaration (1999). It is in the recognition that the training of university teachers must also pass by the pedagogicaldidactical component that some higher education institutions have been conducting training operations for updating, which constitute opportunities for reflection on teaching. This being the problem in this text, we feature in it challenges to teaching in this beginning of the XXI century and analyze an experience developed at the University of Porto, questioning the possibilities of these actions to configure spaces for dialogue between humanistic culture and scientific culture and contribute to a (re)contextualization of the know-how.

Keywords

University teaching; Training of university teacher; Pedagogical and didactical knowledge

FORMATION POUR L'ENSEIGNEMENT UNIVERSITAIRE: UNE RÉFLEXION SUR LE DÉFI D'HUMANISER LA CULTURE SCIENTIFIQUE

Résumé

Pendant les dernières années la formation pédagogico-didactique des professeurs universitaires a constitué un centre d'intérêt pour plusieurs, situation qui était peu commune à ce niveau d'enseignement. L'importance de cette dimension de l'enseignement a été évoquée dans la Déclaration Mondiale sur l'Enseignement Supérieur (1998) et a acquis une plus grande 
expression avec la Déclaration de Bologne (1999). C'est sur la base de la reconnaissance du fait que la formation des professeurs de l'enseignement supérieur doit aussi passer par la composante pédagogico-didactique que certaines institutions d'enseignement supérieur ont mis sur pieds des initiatives d'actualisation qui s'érigent en espaces de réflexion sur l'enseignement. Étant donné que c'est la problématique présente dans ce texte, nous y analysons certains défis qui se posent à l'enseignement en ce début du XXe siècle et nous étudions aussi une expérience développée à I'Université de Porto, problématisant les possibilités qu'ont ces actions pour s'ériger en espaces de dialogues entre la culture humanistique et la culture scientifique et contribuer à une (re)contextualisation de savoir-faire.

Mots-clé

Enseignement universitaire; Formation enseignante universitaire; Connaissance pédagogico-didactique

Recebido em Janeiro/2011 Aceite para publicação em Dezembro/2011 